\title{
Corrigendum: Chromatin-level regulation of biosynthetic gene clusters
}

Jin Woo Bok, Yi-Ming Chiang, Edyta Szewczyk, Yazmid Reyes-Dominguez, Ashley D Davidson, James F Sanchez, Hsien-Chun Lo, Kenji Watanabe, Joseph Strauss, Berl R Oakley, Clay C C Wang \& Nancy P Keller

Nat. Chem. Biol. 5, 462-464 (2009); published online 17 May 2009; corrected after print 18 August 2009

In the version of this article initially published, the fourth author's last name is misspelled. The author's name should read "Yazmid ReyesDominguez." The error has been corrected in the HTML and PDF versions of the article.

\section{Corrigendum: Interactive exploration of chemical space with Scaffold Hunter}

Stefan Wetzel, Karsten Klein, Steffen Renner, Daniel Rauh, Tudor I Oprea, Petra Mutzel \& Herbert Waldmann

Nat. Chem. Biol. 5, 581-583 (2009); published online 28 June 2009; corrected after print 18 August 2009

In the version of this article initially published, reference 10 was incorrect. The correct reference is: Olah, M. et al. in Chemical Biology: from Small Molecules to Systems Biology and Drug Design (eds. Schreiber, S.L., Kapoor, T.M. \& Wess, G.) 760-786 (Wiley-VCH, Weinheim, Germany, 2007). The error has been corrected in the HTML and PDF versions of the article.

\section{Corrigendum: A $21^{\text {st }}$ century revisionist's view at a turning point in enzymology}

Zachary D Nagel \& Judith P Klinman

Nat. Chem. Biol. 5, 543-550 (2009); published online 20 July 2009; corrected after print 20 July 2009

In the version of this article initially published, in the first line in the right-hand column of Box 2, the sentence began "The distance $r_{\mathrm{o}} \ldots$..," whereas it should read "The tunneling distance...." Also, reference 47 was omitted from the end of the second-to-last sentence of the legend of Figure 3. These errors have been corrected in the HTML and PDF versions of the article. 